\title{
Chagas disease in Switzerland: history and challenges
}

Y Jackson (yves.jackson@hcuge.ch) ${ }^{1}, \mathrm{~F}$ Chappuis $^{2}$

1. Division of primary care medicine, Department of community medicine, primary care and emergency medicine, Geneva University Hospitals and University of Geneva, Switzerland

2. Division of humanitarian and international medicine, Department of community medicine, primary care and emergency medicine, Geneva University Hospitals and University of Geneva, Switzerland

Chagas disease, endemic in Latin America, is an emerging health problem in Europe affecting an estimated 80,000 persons. Around 60,000 Latin American migrants live in Switzerland, and cases of Chagas disease have been reported since 1979. As of June 2011, 258 cases have been diagnosed, mostly adults in the indeterminate phase of the chronic stage of the disease. Vertical transmission has been identified and there is a high potential for blood- and organ-borne transmission in the absence of systematic screening. Major challenges include (i) raising awareness among migrants and healthcare professionals, (ii) developing national protocols for screening and treatment targeting high-risk groups such as pregnant woman, newborns, migrants from highly endemic areas (e.g. Bolivia), and immunocompromised migrants, (iii) preventing blood- and organ-borne transmission by appropriate screening strategies, (iv) taking into account the social vulnerability of individuals at risk in the design and implementation of public health programmes, and (v) facilitating contacts with the communities at risk through outreach programmes, for example in churches and cultural groups

\section{Introduction}

The parasite Trypanosoma cruzi, the causative agent of Chagas disease, has been affecting humans for at least 9,000 years, but Europe has experienced the emergence of this disease as a significant health issue only very recently $[1,2]$. In humans, $T$. cruzi is responsible for a chronic infection causing potentially lethal cardiac damages in up to $30 \%$ of cases. It was traditionally confined to the Americas, resulting in a high social and financial burden primarily in rural areas [3]. In the absence of $T$. cruzi vectorial transmission outside Latin America, Chagas disease in non-endemic countries is predominantly an imported infection, affecting migrants more than travellers [4]. Besides, transplacental and blood-borne transmissions have been reported in Europe [5,6]. In 2010, the World Health Organization (WHO) estimated that 80,000 persons could be infected in Europe, making Chagas disease one of the predominant emerging parasitic infections in the continent [2].
In Switzerland, a small country of 7.8 million inhabitants, foreigners accounted for $22.4 \%$ of the total population in 2010. Currently, 35,000 Latin American migrants originating from the 21 countries endemic for Chagas disease are legal residents in Switzerland. This figure does not include adopted children or migrants who have received the Swiss citizenship. Moreover, since the 1990s, a large number of Latin American migrants have been settling in Europe without residence permit and are not recorded in the official registries. For example, 1,229 residents of Bolivian origin were officially registered in Switzerland in 2009, but migrants associations estimate that around 9,000 Bolivians live in the canton of Geneva alone, most of them undocumented ( $F$. Anda, Association des Boliviens de Genève, June 2010, personal communication). A large majority of recent Latin American migrants are women employed in the domestic industry. Thus, it can be estimated that the real number of Latin American migrants at risk of having Chagas disease currently living in Switzerland may be as high as 60,000 to 90,000 [2]. Undocumented migrants are legally entitled to access the Swiss healthcare system by purchasing a health insurance. Yet, the expensive premium (EUR 200-300 per month), lack of knowledge of the system and administrative barriers prevent the vast majority of them from contracting an insurance, thus making access to care difficult, especially outside the main urban areas, where communities and support groups are less organised.

The first recorded case of Chagas disease in Switzerland dates back to 1979 [7]. Since then, the number of cases recorded has increased in parallel with the growth of the population at risk, alongside higher awareness among health professionals and with improved access to reliable diagnostic tools $[8,9]$. Several studies have documented the emergence and transmission of Chagas disease in Latin American communities in Switzerland $[5,10,11]$. Here, we review epidemiological, clinical and social data on all cases of Chagas disease diagnosed and recorded in Switzerland. 


\section{Methods}

We used several sources of information to identify cases and their characteristics before aggregation: (i) the clinical databases of two studies done in Geneva in 2008: a community-based cross-sectional study in adult Latin American immigrants over the age of 16 years [10] and a prospective study in pregnant Latin American women attended at the Geneva University Hospitals [11], (ii) the database of all cases seen at the Geneva University Hospitals and (iii) information collected from the main laboratories performing diagnosis of $T$. cruzi infection, the major Swiss healthcare institutions and experts active in international health and infectious diseases in Switzerland. To optimise data collection, an internet search for published cases was conducted using two major electronic databases (Pubmed and Embase). The keywords 'Switzerland', 'Chagas disease', and 'Trypanosoma cruzi' were used. To avoid duplication of cases from different sources, the date of birth, nationality, sex and place of diagnosis and treatment were cross-checked. Cases were defined as any individual in whom T. cruzi testing was positive, either by serology ( $\geq 9$ month after birth in newborns), nucleic-acid assay or microscopy. Up to 2008, the Swiss Tropical Institute in Basel was the only Swiss laboratory performing serology for T. cruzi infection (in-house indirect immunofluorescent assay), haemoculture and nucleid acid assay (in-house PCR). Since 2008, Geneva University Hospitals have been using two different serological tests (ELISA cruzi, Biomerieux, Brazil and Chagas Stat-Pak, Chembio Diagnostic Systems, United States). Moreover, several Swiss reference laboratories perform microscopical examination in blood and tissues. Since 2008, screening programmes in Geneva have focused on Latin American individuals who fulfil one or more of the following criteria: Bolivian origin, relative of a patient with Chagas disease, suggestive symptoms, recipient of a blood transfusion in the home country, or pregnancy.

\section{TABLE 1}

Socio-demographic characteristics of patients with Chagas disease, Switzerland, January 1979-June 2011 ( $n=258)$

\begin{tabular}{|c|c|}
\hline & $\mathrm{N}(\%)$ or median (range) \\
\hline \multicolumn{2}{|l|}{ Sex } \\
\hline Female & $215(83.3)$ \\
\hline Male & $43(16.7)$ \\
\hline Age & $41(0-77)$ \\
\hline Children ( $\$ 16$ years) & $9(3.5)$ \\
\hline \multicolumn{2}{|l|}{ Country of origin } \\
\hline Argentina & $6(2.3)$ \\
\hline Bolivia & $241(93.4)$ \\
\hline Brazil & $8(3.1)$ \\
\hline Chile & $2(0.8)$ \\
\hline Colombia & $1(0.4)$ \\
\hline $\begin{array}{l}\text { Lack of valid residency permit } \\
\text { (undocumented) }\end{array}$ & $171(97.1)$ \\
\hline
\end{tabular}

a Denominator $=176$.

\section{Results}

Number of cases and place of diagnosis

From 1979 to June 2011, a total of 258 persons have been diagnosed with $T$. cruzi infection in Switzerland. All but five patients were diagnosed in Geneva.

Time variation of frequency of cases and clinical features

From 1979 to 2007, in the absence of screening programmes, 11 cases of $T$. cruzi infection had been identified including eight symptomatic cases: five with cardiac, one with cardiac and digestive complications, and two congenital infections with placental abnormalities [5,7-9]. After screening programmes were initiated in Geneva, 247 cases were diagnosed from January 2008 to June 2011, with a lower proportion of symptomatic cases ( 53 of the 231 clinically evaluated patients).

\section{Socio-demographic characteristics}

Table 1 shows the socio-demographic characteristics of the 258 patients. The median age was 41 years and women were overrepresented with $83 \%$ of cases. The vast majority of patients were Bolivians $(n=241)$. Information on whether they had a residence permit was available for 176 patients. Most of those $(n=171)$ were living in Switzerland without a residence permit and without health insurance.

\section{Mode of transmission and clinical staging}

Congenital transmission (acute phase) was diagnosed in four newborns, all of them from Bolivian mothers. In addition, five children between 1 and 11 years of age were diagnosed at the early indeterminate phase of the chronic stage. Table 2 shows the clinical staging of the 258 patients. One fatal case occurred following a fulminant $T$. cruzi infection reactivation in an immunosuppressed patient who had received a heart transplant [10].

\section{Diagnosis}

All patients in the indeterminate phase of the chronic stage and one newborn (aged nine months) were

\section{TABLE 2}

Clinical staging of patients with Chagas disease, Switzerland, January 1979-June 2011 ( $\mathrm{n}=258)$

\begin{tabular}{|l|c|}
\hline Stage & $\mathrm{N}(\%)$ \\
\hline Acute - congenital & $4(1.6)$ \\
\hline Acute - reactivation & $1(0.4)$ \\
\hline Chronic - early indeterminate & $5(2)$ \\
\hline Chronic - indeterminate & $178(69)$ \\
\hline Chronic with cardiac involvement & $51(19.8)$ \\
\hline Chronic with digestive tract involvement & $3(1.2)$ \\
\hline Chronic with cardiac and digestive tract involvement & $1(0.4)$ \\
\hline Information not available & $15(5.6)$ \\
\hline
\end{tabular}


diagnosed by positive results in at least one, mostly two, serological assays (immunofluorescence, ELISA or immunochromatography) with the strategies or combinations varying depending on the diagnosing centre. One newborn was diagnosed by positive T. cruzi nucleic acid test of umbilical cord blood. Two other newborns were diagnosed by detection of amastigote forms of $T$. cruzi in the placenta with confirmation by positive serology and nucleic acid assay. The patient with $T$. cruzi reactivation was diagnosed by identifying amastigote forms in the skin and in a bone marrow biopsy, and by a positive peripheral blood buffy coat.

\section{Treatment}

Criteria for treatment initiation were based on recommendations from the World Health Organization and on guidelines from the United States [11,12]. Until 2009, nifurtimox was used for availability reasons. Since then, benznidazole has been more easily available and has become the first-line treatment. Anti-parasitic treatment was initiated in 129 patients (50\%). Ninetythree patients received nifurtimox ( $10 \mathrm{mg} / \mathrm{kg} / \mathrm{day})$ and 36 received benznidazole $(5 \mathrm{mg} / \mathrm{kg} /$ day; $\max : 300 \mathrm{mg} /$ day). Overall, adverse events caused premature treatment termination (less than 60 days) in 41 patients (31.8\%; nine with benznidazole and 32 with nifutimox). A full description on tolerance of nifurtimox in patients treated in Switzerland has been published [13].

\section{Discussion}

To our knowledge, 258 cases of Chagas disease were diagnosed and recorded in Switzerland between 1979 and 2011. Considering the limited number of medical centres and laboratories working on parasitic diseases in Switzerland, this figure probably reflects the actual situation correctly. Almost all cases were diagnosed in Geneva, which has several reasons: (i) a large community of Bolivian migrants live in Geneva, (ii) local policies allow access to primary healthcare for uninsured individuals, (iii) repeated epidemiological investigations on Chagas disease and information sessions with the community have created confidence and reinforced the cooperation between migrants and the Geneva University Hospitals (HUG), (iv) screening programmes have been implemented in the Canton of Geneva. Such programmes have so far not been put in place in blood banks, maternity wards and health institutions of other Swiss cantons, with the exception of Lausanne in the Canton of Vaud. The implementation of screening in Geneva is the main explanation for the shift from a low number of detected cases with a high proportion of symptomatic individuals (until 2007) to a higher number of cases with a high proportion of asymptomatic individuals (since 2008). Previous studies in Geneva showed $25 \%$ prevalence within the Bolivian community, mostly in women of child-bearing age who had a positive attitude towards blood donation in Geneva, which highlighted the risk of blood-borne and congenital transmission [5,14].
Chagas disease represents an emerging and complex health issue in Switzerland considering (i) the presence of a significant number of infected persons, (ii) their social situation with poor access to healthcare and very low socioeconomic status, (iii) the active vertical transmission and the potential for transmission through blood and organ donations, and (iv) the low awareness and consideration by public health authorities and health professionals [15]. The situation of Chagas disease in Switzerland is emblematic of the European context, as until now only Spain and France have adopted public health policies to control the spread of this emerging infection [16]. National recommendations or programmes of case detection and management or prevention of local transmission do not currently exist in Switzerland. Specific tests to diagnose chronic Chagas disease are available in a limited number of laboratories. Neither of the two drugs active against $T$. cruzi, benznidazole and nifurtimox, are registered by the Federal Pharmaceutical Office and thus require specific agreement for each treatment, nor are they easily available.

Since 2008 , some progress has been made regarding the management of Chagas disease in Switzerland. Serologies are now available in two laboratories (HUG and the Swiss Tropical and Public Health Institute in Basel). A rapid diagnostic test has been validated and is being used in HUG and the University Hospital of Lausanne [17]. Systematic screening of Latin American pregnant women was first implemented at HUG in 2008 , followed in 2010 by a wider strategy of screening all persons at risk, i.e. Latin American immigrants, persons who received blood transfusion in Latin America or persons born to a Latin American mother. In 2011, the University Hospital of Lausanne is expected to adopt similar protocols. Systematic screening of blood donors at risk is under discussion at local (Geneva, Lausanne) and national levels. Ties with Latin American communities have been strengthened through information exchange and awareness campaigns. Education of medical students and health professionals through clinical meetings, presentations in congresses and publications in national medical journals has been initiated.

Considering the number of Latin American immigrants living in Switzerland and the proportion of $T$. cruzi infections in this community, up to 3,000 cases could be present in the country. The main challenges for the control of this emerging health threat are: (i) raising awareness both in communities at risk of infection and in health professionals, e.g. primary care physicians, gynaecologists/obstetricians, paediatricians, cardiologists, gastroenterologists, and radiologists, (ii) developing national protocols for screening and treatment, targeting high-risk groups such as pregnant woman, newborns, Bolivian citizens, immunosuppressed migrants, (iii) preventing blood- and organ-borne transmission by appropriate screening strategies, (iv) taking into account the social vulnerability of individuals at 
risk in the design of programmes and their implementation, and (v) facilitating contacts with the communities at risk through outreach programmes, for example in churches and cultural groups.

\section{Acknowledgments}

The authors wish to thank Hanspeter Marti (Swiss Tropical and Public Health Institute, Basel, Begona Martinez de Tejada, Cristina Reis, Alessandro Diana, Anne Mauris and Claire-Anne Wyler (Geneva University Hospitals) and Valérie D’Acremont (CHUV Lausanne) for helping gathering information

\section{References}

1. Aufderheide AC, Salo W, Madden M, Streitz J, Buikstra J, Guhl F, et al. A 9,000-year record of Chagas' disease. Proc Natl Acad Sci U S A. 2004;101(7):2034-9.

2. World Health Organisation (WHO). Statement - Chagas disease in Europe. Geneva: WHO; 20 January 2010. Available from: http://www.who.int/neglected_diseases/integrated_media_ chagas_statement/en/index.html

3. Hotez PJ, Bottazzi ME, Franco-Paredes C, Ault SK, Periago $M R$. The neglected tropical diseases of latin america and the Caribbean: a review of disease burden and distribution and a roadmap for control and elimination. PLoS Negl Trop Dis. 2008;2(9):e300.

4. Lescure FX, Le Loup G, Freilij H, Develoux M, Paris L, Brutus L, et al. Chagas disease: changes in knowledge and management. Lancet Infect Dis. 2010;10(8):556-70.

5. Jackson Y, Myers C, Diana A, Marti HP, Wolff H, Chappuis F, et al. Congenital transmission of chagas disease in latin american immigrants in Switzerland. Emerg Infect Dis. 2009;15(4):601-3.

6. Flores-Chavez M, Fernandez B, Puente S, Torres P, Rodriguez M, Monedero C, et al. Transfusional chagas disease: parasitological and serological monitoring of an infected recipient and blood donor. Clin Infect Dis. 2008;46(5):e44-7.

7. Liechti M, Baur HR, Gurtner HP, Straub PW. Cardiac complications of American trypanosomiasis (Chagas disease). Various case reports and general observations. Schweiz Med Wochenschr. 1990;120(41):1493-6.

8. Jackson Y, Chappuis F, Loutan L. [Chagas disease in Switzerland: managing an emerging infection and interrupting its transmission]. Rev Med Suisse. 2008;4(157):1212-4, 6-7. French.

9. Sztajzel J, Cox J, Pache JC, Badaoui E, Lerch R, Rutishauser W. Chagas' disease may also be encountered in Europe. Eur Heart J. 1996;17(8):1289. Eur Heart J. 1996 Aug;17(8):1289.

10. Jackson Y, Dang T, Schnetzler B, Pascual M, Meylan P. Trypanosoma cruzi fatal reactivation in a heart transplant recipient in Switzerland. J Heart Lung Transplant. 2010;30(4):484-5.

11. Bern C, Montgomery SP, Herwaldt BL, Rassi A Jr., Marin-Neto JA, Dantas RO, et al. Evaluation and treatment of chagas disease in the United States: a systematic review. JAMA. 2007;298(18):2171-81.

12. World Health Organisation (WHO) Expert Committee on the Control of Chagas disease (2000: Brasilia, Brazil). Control of Chagas disease: second report of the WHO expert committee. WHO technical report series; 905. Geneva: WHO; 2002. Available from: http://whqlibdoc.who.int/trs/WHO_TRS_905. pdf

13. Jackson Y, Alirol E, Getaz L, Wolff H, Combescure C, Chappuis F. Tolerance and safety of nifurtimox in patients with chronic chagas disease. Clin Infect Dis.;51(10):e69-75.

14. Jackson Y, Getaz L, Wolff H, Holst M, Mauris A, Tardin $A$, et al. Prevalence, clinical staging and risk for blood borne transmission of Chagas disease among Latin American migrants in Geneva, Switzerland. PLoS Negl Trop Dis.2010;4(2):e592.

15. Jackson Y, Angheben A, Carrilero Fernandez B, Jansa i Lopez del Vallado JM, Jannin JG, Albajar-Vinas P. [Management of Chagas disease in Europe. Experiences and challenges in Spain, Switzerland and Italy]. Bull Soc Pathol Exot. 2009;102(5):326-9.

16. Castro E. Chagas'disease: lessons routine donation testing. Transfus Med 2009;19(1):16-23.
17. Chappuis F, Mauris A, Holst M, Albajar-Vinas $P$, Jannin J, Luquetti AO, et al. Validation of a rapid immunochromatographic assay for diagnosis of Trypanosoma cruzi infection among Latin-American Migrants in Geneva, Switzerland. J Clin Microbiol.;48(8):2948-52. 